\title{
Research trends in biomimetic medical materials for tissue engineering: 3D bioprinting, surface modification, nano/ micro-technology and clinical aspects in tissue engineering of cartilage and bone
}

\author{
Cen Chen ${ }^{1+}$, Sumi Bang ${ }^{2+}$, Younghak Cho ${ }^{3}$, Sahnghoon Lee ${ }^{4}$, Inseop Lee ${ }^{1,5}$, ShengMin Zhang ${ }^{6}$ and Insup Noh 2,7* $^{*}$
}

\begin{abstract}
This review discusses about biomimetic medical materials for tissue engineering of bone and cartilage, after previous scientific commentary of the invitation-based, Korea-China joint symposium on biomimetic medical materials, which was held in Seoul, Korea, from October 22 to 26, 2015. The contents of this review were evolved from the presentations of that symposium. Four topics of biomimetic medical materials were discussed from different research groups here: 1) 3D bioprinting medical materials, 2) nano/micro-technology, 3) surface modification of biomaterials for their interactions with cells and 4) clinical aspects of biomaterials for cartilage focusing on cells, scaffolds and cytokines.
\end{abstract}

\section{Introduction}

Scaffolds with bimimetics have been developed for tissue engineering, based on the sciences and engineering of biomaterials and nano/microstructures of defect tissues. The bone and cartilage tissues function according to the physicochemical properties and nano/micro-structures of tissues. Surface and bulk morphologies, defect sizes, extracellular matrix (ECM) domains, biological molecules and ECM structures are typical examples of major components and properties of defect tissues, which require tissue regeneration. 3D bioprinting among many technologies in tissue engineering has been applied to fabrications of scaffolds based on understanding of tissue morphologies and physicochemical properties in nano/micro levels, even though 3D bioprinting has at current stages many huddles to be overcome to its clinical applications. Tissue engineering of 3D

\footnotetext{
* Correspondence: insup@seoultech.ac.kr

${ }^{\dagger}$ Equal contributors

${ }^{2}$ Seoul National University of Science and Technology, 232

Gongneung-roNowongu, Seoul 11811, Republic of Korea

${ }^{7}$ Department of Chemical and Biomolecular Engineering, Seoul National University of Science and Technology, 232 Gongneung-ro, Nowon-gu, Seoul 01811, Republic of Korea

Full list of author information is available at the end of the article
}

printing scaffolds could be clinically accomplished by combining with (stem) cells, possibly with biological agents. In this review, we in different research groups have briefly discussed recent research trends in biomimetic medial materials for tissue engineering such as 3D bioprinting, surface modification, nano/micro-technology and clinical aspects in tissue engineering of bone and cartilage. Their backgrounds are designs of biomaterials in nanotechnology, fabrications of tissue engineering, surface modification and orthopedic clinics.

\section{Research trends of biomimetic medical materials: 3D bioprinting}

Tissue engineering is repairing or regenerating diseased or damaged tissues and organs through implantation of the combinations of tissue engineering factors such as cells, scaffolds and biological signals with mechanical stimuli. Tissue engineering scaffolds provide primarily 3D structures of specific tissues and support tissue regeneration via cell adhesion, proliferation, and cellular communications and interactions. Porous polymer scaffolds for bone and cartilage regeneration have been traditionally fabricated through the methods of 
gas forming, soluble particle leaching and freeze drying [1-3]. Those methods have been developed by using functional chemistries and surface modifications of polymeric biomaterials. Porous scaffolds of biodegradable poly(lactide-co-glycolide) were fabricated by gas foaming of porogens such as ammonium bicarbonate particles. Injectable hydrogel was developed by using click chemistry, showing its advantages such as local delivery of bioactive molecules, easy handling, minimal invasiveness, and its potential applications to 3D bioprinting materials [4].

Fabrications of tissue engineering scaffolds have been recently focused on both utilization of biomimetic of extracellular matrix (ECM) and control of both cellular behaviors and biosignals. Novel fabrication methods of well-defined scaffolds have been reported for large tissue defects and organ replacement by using acellular scaffolds or cellular constructs $[5,6]$. While acellular scaffolds were fabricated using various techniques such as heat, chemicals, light and molding, cellular constructs were done by combinations of cells and mostly photo-printing of hydrogels in 3D printing to mimic the properties of ECM of bone and cartilage. 3D printing of scaffolds was achieved by the methods of material extrusion, material jetting, binder jetting, sheet lamination, vat photo-polymerization, powder bed fusion and direct energy deposition $[7,8]$. These methods have their own pros and cons in their applications to fabricating tissue engineering scaffolds. Stereolithography and fused deposition methods have disadvantages such as difficulty in bioprinting of precursor polymer solutions with live cells due to their damages during printing and side effects of cross-linking agents during hydrogel formation $[9,10]$. In the case of vat photo-polymerization, active and non-toxic cross-linking agents are required for hydrogel fabrications, and at the same time, structural integrity of implanted scaffolds between scaffold biodegradation and tissue regeneration is important over in vivo implant periods. Syringe extrusion of cells complex during inkjet 3D printing is achieved by the methods of air pressure, syringe pump and screw, and cells-containing hydrogel is currently printed out with a dimension of $100 \mu \mathrm{m}-1 \mathrm{~mm}$ ranges in diameters $[11,12]$. While those extrusion methods have advantages such as mechanical properties and possibility of combinations of biomaterials and cells, they also have limited properties such as shear stress to the wall of a nozzle tip and limited choices of hydrogel materials for cell encapsulation, leading to cells aggregation and damages.

Diverse biomaterials have been developed in 3D bioprinting of scaffolds [13-16]. While natural polymers such as collagen, hyaluronic acid, chitosan, cellulose, fibrin, alginate, agarose, gelatin, laminin and matrigel have been employed in 3D bioprinting through their chemical modifications, poly(ethylene glycol) poly(lactide-co-glycolide), polylactide, polycarprolactone, polyglycolide and poly(vinyl alcohol) have been employed as synthetic polymers for tissue engineering of bone and cartilage. Applications of biomimetics to hydrogel fabrication in bioprinting were possible by chemical modifications of biocompatible polymers such as poly(ethylene glycol), polycarbonates and poly(vinyl alcohol) among many synthetic medical polymers. Functional cross-linking of the polymers were possible through click chemistries such as photo- and thermal chemistry, Michael type addition reactions, $\mathrm{pHs}$ and others [17-21]. Inorganic biomaterials have been also employed for 3D printing by controlling the properties of 3D printers such as fabrication methods and their nozzle sizes and surface properties [22, 23]. Bioactive glass, hydroxyl apatite, biphasic calcium phosphate, hydroxyphosphate calcium and tricalcium phosphate were normally employed as inorganic biomaterials in 3D printing of scaffold for tissue engineering. Recently, combinations of those polymers and ceramics have been tried to optimize their properties for 3D bioprinting.

Combination of 3D bioprinting and micro/nano-technology has been utilized in tissue engineering area, being considered as a unique technology to overcome the issues of fabrications of biomimetic scaffolds for complex tissues. $\mathrm{Nano} /$ micro-technology has been employed for designs of scaffolds as described in following session. Controlling of porosity, permeability, surface properties, initial mechanical properties, and biodegradation of repeating units in polymer's backbone chains are examples of employment of nano/micro-technology in scaffold designs [24-27]. 3D bioprinting uses hydrogel as a cell carrier and requires properties such as high cell viability, surface tension, water contents and printability with high resolution with tens to hundreds of $\mu \mathrm{m}$ [28]. It provides new approaches towards better and smarter tissue engineering that have the possibility to profoundly impact therapeutic regenerative medicine through better biomimetics of specific tissue structures by nano/micro-technology. Since cells and their components are in the ranges of tens to hundreds micrometers to nano-meters, cell-biomaterials interactions are affected by those ranges, indicating the importance of biomaterials designs and fabrications through combination of micro/nano-technology and biomimetics. Important factors in biomimetics-based scaffolds designs could be controlled delivery of bioactive molecules, fabrications of right pore size, volume and geometry similar to target ECM as well as biomaterials compositions and physical/ chemical properties of the scaffolds [29-32]. Biomimetic scaffolds have been reported having defined mechanical/ structural properties of bone tissues such as properties of the cancellous bone's $50-90$ volume \% porosity and the cortical bone's dense outer layer of bone with less than 10 volume $\%[11,12]$. In cartilage, example of combination of biomimetics and nano/micro-technology is designing the structures of cartilage tissues through 3D bioprinting as well as their bio-related chemical and mechanical 
functions [30]. These functional designs of scaffolds with controlled delivery of biosignals have been expected to lead to better regeneration of various zones of osteochondral ECM.

Even though remarkable progresses was made in tissue engineering by using both 3D bioprinting and nano/microtechnology, there are still huddles, such as the issues of adequate printable biomaterials, biocompatibility, structural stability, biodegradation and immunology, to be overcome in the area of clinical applications to tissue engineering of bone and cartilage among many target tissues. Better cooperation of biomaterials scientists, engineers and clinicians should be made to achieve progress of 3D bioprinting and bone and cartilage tissue engineering.

\section{Research trends of biomimetic medical materials: micro/ nano-patterning technology}

There exist largely two approaches to make micro/nano patterns. One is top-down approaches; They use usually the templates which are fabricated through UV photolithography, nanolithography [33-35] such as e-beam lithography, nanoimprint lithography and focused ion beam (FIB) milling, and so on. However, the nanolithographybased top-down approaches for nanoscale patterns suffer from low throughput and high cost. Therefore, a simple and cost-effective process with high throughput is required for the fabrication of well-defined micro/nano patterns. The other approaches, which are called as bottom-up approaches, are generally free from complex template fabrication. They include electrospinning, selfassembly, wrinkle and crack through PDMS stretching, electrodeposition and sol-gel synthesis with anodic aluminum oxide (AAO) or copolymer templates [36-41]. They can make micro/nano patterns in a simple, highthroughput and cost-effective manner, but suffer from obtaining the ordered and reproducible patterns when compared with those of the top-down approaches.

Many researches have been reported about development of micro/nano patterns for biomedical applications using both top-down and bottom-up approaches [42-45]. Specially, polymer-based micro/nano patterns have been widely used for those fields because polymer-based materials have the advantages of low cost, good biocompatibility, high optical clarity and high impact strength [46-48]. Recently, biological materials such as diatom [47] and galium aparine [48] are increasingly used as templates for replica molding process, which enable us to fabricate micro/nano patterns and features with low-cost and high reliability. Also, conventional direct etching process to biomedical materials such as titanium ( $\mathrm{Ti}$ ) is effective to obtain micro/nano structures on its surface [49]. The successful construction of micro/nano-textured surface on a Ti substrate could induce cell adhesion and proliferation efficiently. Recently, nanostructured biomaterials with physical nano-features (nanocrystals, nanofibers, nanocomposites, etc.) have been widely studied in the fields of regenerative medicine due to the resemblance of physical nano-features to natural ECM [50, 51]. Since natural biological tissues, organs and cells have nanoscale features, the biomimetic features and excellent physicochemical properties of nanostructured biomaterials play a key role in stimulating cell growth as well as guiding tissue regeneration [52]. Therefore, the surface designs in nanoscale and molecular level are very important in developing new functional biomaterials.

\section{Biomimetic medical materials trends: surface modifications}

Natural materials like bone, ligaments, wood, shells, and scales are remarkably efficient in terms of fulfilling complex and multiple functional requirements [53]. The development of biomaterials has recently focused on the design of biomimetic materials that are capable of eliciting specific cellular responses and directing new tissue formation mediated by bioactive molecules recognition, which can be manipulated by altering design parameters of the material [54]. For example, an implant associates osteoinductive biomolecules, such as growth factors, hormones, enzymes and DNAs, with osteoconductive calcium phosphates, could regulate and accelerate the bone formation.

Extensive studies have been performed to render materials' biomimetic. The surface modification of biomaterials with bioactive molecules is a simple way to make biomimetic materials [55]. There are various techniques to immobilize bioactive molecules onto the surfaces of biomaterials, including physical adsorption [56], chemically covalent bonding [57], and biomimetic incorporation [58]. Biomimetic coating has been first introduced by Kokubo in 1990s through soaking alkali treated implants in a simulated body fluid (SBF: ion concentrations similar to human blood plasma) resulting in growth of a bone-like apatite layer [59]. The generated minerals, being biodegradable, porous, and microcrystalline, have the ability to load bioactive molecules onto substrate without compromising their bioactivity. As consequence, the bioactive molecules are truly incorporated into the crystal lattice, not superficially adsorbed upon surfaces. The molecules are released gradually from these coating, rather than in a single rapid burst. One remarkable advantage of the biomimetic coating is that it can even grow on three-dimensional scaffolds.

Surface modification with bioactive molecules offers the potential to control cell behavior only on the surface of biomedical devices. With bulk modification of biomaterials, bioactive molecules are incorporated into the biomaterials and the resulting recognition sites are present not only on the surface but also in the materials [60]. It is well known that the formation of a turban shell includes a process where inorganic minerals deposited on assembled organic 
proteins from an aqueous solution at mild temperature and pressure [61]. If this type of biomimetic approach could be reproduced, then the bioactive molecules could be incorporated stably in inorganic materials without losing their biological activity [62]. Various bioactive molecules, such as collagen [63], silk fibroin [64], dentin matrix protein 1 [65], chitosan [66], alginate [67], peptide-amphiphile molecular [68], have been served as templates to regulate the growth of inorganic crystals. The structures of the templates play a vital role in controlling the morphologies of the inorganic crystals [69]. For example, fibrous templates lead to a needle-like hydroxyapatite [70], while spherical templates result in sheet-like hydroxyapatite [71]. Simultaneous applying different templates in the system may lead to more sites of nucleation compared with a single-template system, which may affect the orientation, size, and morphology of regulated inorganic crystal.

Biomimetic medical materials with immobilized bioactive molecules possess unique properties of organic and inorganic components in one material for academic research as well as for the development of innovative industrial applications. Thus, the surface modification of metal or bulk modification of ceramic with bioactive molecules is necessary to produce high-performance biomimetic medical materials.

\section{Recent research trends of articular cartilage repair: cells, scaffolds and cytokines}

The predominant approach for tissue regeneration is cell delivery, either by transplantation of progenitor cells or more mature cells. Many cell sources have been explored for the treatment of cartilage defect whether they are either autologous or allogenic. Autologous cells that are clinically available for articular cartilage repair are chondrocytes. Autologous chondrocyte implantation (ACI) was first published in 1994 by Brittberg and it has been expected to show far better results than the marrow stimulating procedure [72, 73]. Autologous chondrocyte implantation, however, was also not perfect and showed the results comparable to or slightly better than those of marrow stimulating procedure in several studies [74]. Fibrous cartilage regeneration, difficulty in procedure and high cost for cell preparation are hurdles in widespread use of this technique [75]. More cell sources including autologous bone marrow cells and adipose stem cells are under investigation and clinical trials, although the evidences are limited so far [76]. Cartilage itself has been shown to have stem cell fraction in their matrix, but they are too few and little has been known about their biological potentials in regenerating tissue [77].

Allogenic cells can be used after ex vivo culture and considered to be different from autologous cells in their behaviors in vivo [78]. These allogenic cells remain as an attractive alternative that circumvents the problem of donor cell shortage. There are, however, technical problems such as immunogenicity, pathogen transmission and mismatch of donor-host micro-environment, which should be resolved prior to clinical applications. Recently allogenic cord blood stem cells have been commercialized in Korea to repair articular cartilage repair for chondral defects as well as degenerative articular diseases. Although the efficacy compared with other regenerative techniques is still in questions, its safety and the minimal efficacy have been accepted by the government agency for permission to be used for patients with chondral defects.

In contrast to the exogenously administered/injected cells, a micro-fracture technique has been considered as a representative surgical procedure that uses endogenous cells in cartilage repair [79]. Simple micro-fractures or subchondral drilling provides a complete set of constituents required for tissue-engineered cartilage regeneration theoretically. However, incomplete healing of the defects, deterioration of the fibrocartilage, and subchondral bone hypertrophy after micro-fracture resulted in unsatisfactory clinical outcomes that necessitated improvement of the methods or the development of novel sources of constituents [80, 81]. Various biomaterials scaffolds that provide temporary compartment to retain cells and enable diffusion of vital nutrients were developed to enhance potentials of tissue regeneration by micro-fracture techniques [82]. Autologous bone marrow cells can be harvested from ilium, concentrated and then applied, thus providing higher number of cells to participating tissue regeneration [83]. Their results are controversial and well-designed level 1 studies are scarce, but several promising results showed potentials of their applications. It is still controversial whether the cultured chondrocytes are better than endogenous bone marrow cells. Several randomized clinical trials showed no differences in outcomes between micro-fracture and ACI, while others did although it is small [84].

Polymeric biomaterials scaffolds were used to eliminate complications and to promote the outcomes of ACI [85]. Collagen sheets and hyaluronic acid gels among other scaffolds were expected to reduce the hypertrophic complications of periosteum that was used for ACI. In general, the $2^{\text {nd }}$ and $3^{\text {rd }}$ generation ACIs that used biomaterial scaffolds showed tendency toward better outcome than its $1^{\text {st }}$ generation did. Scaffolds such as hyaluronan have been used to enhance the outcomes of micro-fracture. Autologous matrix-induced chondrogenesis (AMIC) showed better mid to long term results than micro-fracture only did [82].

Collagen and fibrin also function as bioactive cues like growth factors or cell recruitment factors. Bioactive cues to initiate and enhance the regeneration potential have been considered as one of the most important issues that should be addressed. Whereas the cell transplantation is 
still the predominant approach, emerging studies have shown enhanced potentials of host endogenous cells. Cell homing is the concept that cells such as mesenchymal stem cells (MSCs) migrate to injured tissue as MSCs express various chemokine receptors and adhesion molecules [86]. Its attracting factors are numerous. Recently an acellular 'smart' scaffold with TGF- $\beta_{3}$ has been reported to regenerate whole synovial joint including bone, cartilage and synovium [87]. Also, poly(lactide-co-glycolide) (PLGA) scaffolds seeded with autologous endothelial progenitor cells have shown to repair a full-thickness osteochondral defect in rabbits [88].

Cell transplantation and cell homing are not exclusive each other in cartilage tissue engineering. Furthermore, engineered scaffolds are required to provide a provisional space for effective tissue regeneration as well as manipulation of appropriate bio-environments.

\section{Conclusions}

Four topics of biomimetic medical materials from different research groups with different backgrounds have been discussed such as 1) 3D bioprinting focusing on medical materials, 2) designs of nano/micro-technology, 3) surface modification of biomaterials for their interactions with cells, and 4) clinical aspects of biomaterials for cartilage focusing on cells, scaffolds and cytokines. Even though traditional methods of fabrications of tissue engineering scaffolds have still many advantages, 3D printing methods and right biomaterials have been emerged as extremely important factors in tissue engineering, where both designs of biomaterials in micro/ nano levels and surface modifications have acted as the basic technologies in designs of biomimetic materials. Combination of 3D printing and stem cells are extremely important to tissue engineering of bone and cartilage tissues.

\section{Competing interests}

The authors declare that they have no competing interests.

\section{Authors' contributions}

ISN and SMZ organized and worked on the 2016 Korea-China Joint Symposium on Biomimetic Medical Materials and organized the manuscript. The authors in each review session contributed their own parts. ISN has organized all the parts of this manuscript and all the authors read and approved the final manuscript. ISN, Korea side, and SMZ, China side, are the chairmen of 2015 Korea-China Joint Symposium of Biomimetic Medical Materials in Korea.

\footnotetext{
Authors' information

Insup Noh, Ph.D., is a professor of department of chemical and biomolecular engineering and the founder/director of the Convergence Institute of Biomedical Engineering and Biomaterials in Graduate School, Seoul National University of Science and Technology, Republic of Korea, co-operated with Korea Institute of Radiological and Medical Sciences. He earned his MSE and Ph.D. degrees at University of Texas at Austin, USA. He worked in both California Institute of Technology as a special graduate student and in Division of Harvard-MIT Health Science and Technology as a postdoctoral fellow. He is currently vice presidents of both the Korean Society for Biomaterials and the Korean Tissue Engineering and Regenerative Medicine Society, serving as both an editor-in-chief of Biomaterials Research and a regional editor of the Open
}

Biomedical Engineering Journal. Ms. Sumi Bang is a graduate student in the Convergence Institute of Biomedical Engineering and Biomaterials in Seoul National University of Science and Technology, Korea.

Younghak Cho, Ph.D., is an associate professor of the Department of Mechanical System Design Engineering, Seoul National University of Science and Technology (Seoul Tech), Republic of Korea. Dr. Cho received B.S. and M.Eng. degrees from Mechanical Engineering in Seoul National University, Korea, in 1999 and 2001, and the Ph.D. degree from Precision Engineering in The University of Tokyo, Japan, in 2005. From April 2005 to August 2007, he was with the Institute of Industrial Science, The University of Tokyo, as JSPS Postdoctoral Researcher. From October 2007 to February 2009, he was with the Department of Electrical and Computer Engineering, Texas A\&M University, as Postdoctoral Research Associate. He joined Seoul Tech in 2009. His current research interests include the development of nanostructures such as nanowire and nanoimprinting mold and its application to nanowire-based sensors such as UV-sensor, biosensor and chemical sensor. In-Seop Lee, Ph.D., is currently at the Institute of Natural Sciences in Yonsei University, Republic of Korea. He received Ph.D. degree from the Department of Materials Science \& Engineering in the University of Tennessee at Knoxville, USA in 1989. He was employed at Korea Workers Medical Center as a principal research scientist before joining to Yonsei University. His research interests are to develop materials for medical applications, and have focused on improving the bio-implant interface. He serves as editors-in-chief for the international journal of Biomedical Materials (IF=3.697): Materials for tissue engineering \& regenerative medicine published by Institute of Physics (http://www.iop.org/EJ/bmm).

Cen Chen, Ph.D., is an assistant professor of Bio-X Center, College of Life Sciences, Zhejiang Sci-Tech University, Hangzhou, People's Republic of China. Sahnghoon Lee, M.D., Ph.D. currently serves as an associate professor at Seoul National University College of Medicine, Republic of Korea. He graduated and received Ph.D. degree from Seoul National University College of Medicine. He was trained at the Department of Orthopaedic Surgery, Seoul National University Hospital after obtaining medical license. His research interest focused on cartilage tissue engineering and regeneration using chondrocytes and synovial stem cells.

Shengmin Zhang, Ph.D., currently serves as the Chair Professor of Biomedical Materials at Huazhong University of Science and Technology, China. He received his Ph.D. in Biomedical Materials from Wuhan University of Technology, China. He became a professor, then the Chair Professor and Director of the Advanced Biomaterials and Tissue Engineering Center at Huazhong University of Science and Technology in Wuhan, China, from 2003. His previous other positions were a professor (2000-2003), an associate professor (1996-2000) and an assistance professor (1992-1996) at the Materials Science Department in Wuhan University of Technology. He has over 20-year experience in biomaterials and tissue engineering fields and is the Chairman of Regenerative Medical materials Committee, Chinese Society for Biomaterials (CSBM) and CSBM Chairman of Science Popularization Committee. He serves on the editorial boards of several well- established international journals, such as Tissue Engineering (Part A, B and C, USA), Biomedical Materials (IOP, UK), etc.

\section{Acknowledgement}

These works have been developed from the 2015 Korea-China Joint Symposium on Biomimetic Medical Materials, Seoul, Korea. These works were supported by the Grants of both the National Research Foundation of Korea (NRF) (2014K2A2A7060928) and the Natural Science Foundation of China (NSFC; No. 81461148032)

\section{Author details}

'Bio-X Center, College of Life Sciences, Zhejiang Sci-Tech University, Hangzhou, People's Republic of China. ${ }^{2}$ Seoul National University of Science and Technology, 232 Gongneung-roNowongu, Seoul 11811, Republic of Korea. ${ }^{3}$ Department of Mechanical System Design Engineering, Seoul National University of Science and Technology, 232 Gongneung-ro, Nowon-gu, Seoul 11811, Republic of Korea. ${ }^{4}$ Department of Orthopaedic Surgery, Seoul National University College of Medicine/Seoul National University Hospital, Seoul 110-799, Republic of Korea. ${ }^{5}$ nstitute of Natural Sciences, Yonsei University, Seoul 03722, Korea. ${ }^{6}$ Advanced Biomaterials and Tissue Engineering Center, Huazhong University of Science and Technology, Wuhan, P. R. China. ${ }^{7}$ Department of Chemical and Biomolecular Engineering, Seoul National University of Science and Technology, 232 Gongneung-ro, Nowon-gu, Seoul 01811, Republic of Korea. 


\section{Received: 4 February 2016 Accepted: 7 April 2016 Published online: 04 May 2016}

\section{References}

1. Chatterjee K, Kraigsley AM, Bolikal D, Kohn J, Simon Jr CG. Gas-foamed scaffold gradients for combinatorial screening in 3D. J Funct Biomater. 2012:3:173-82.

2. Barbanti SH, Zavaglia CAC, Duek EAR. Effect of salt leaching on PCL and PLGA(50/50) resorbable scaffolds. Mater Res. 2008;11(2):75-80.

3. Haugh MG, Murphy CM, O'Brien FJ. Novel freeze-drying methods to produce a range of collagen-glycosaminoglycan scaffolds with tailored mean pore sizes. Tissue Eng Part C Methods. 2010;16(5):887-94.

4. Jo S, Kim S, Noh I. Synthesis of in situ chondroitin sulfate hydrogel through phosphine-mediated Michael type addition reaction. Macromol Res. 2012:20:968-76.

5. Macadam SA, Lennox PA. Acellular dermal matrices: Use in reconstructive and aesthetic breast surgery. Can J Plast Surg. 2012;20(2):75-89.

6. Lee KBL, Hui JHP, Song IC, Ardany L, Lee EH. Injectable mesenchymal stem cell therapy for large cartilage defects-A porcine model. Stem Cells. 2007;25:2964-71.

7. Chia HN, Wu BM. Recent advances in 3D printing of biomaterials. J Biol Eng. 2015;9:4.

8. Balogun VA, Kirkwood ND, Mativenga PT. A review on powder bed fusion direct electrical energy demand in fused deposition modelling. Procedia CIRP. 2014;15:38-43.

9. Lee KW, Wang S, Fox BC, Ritman EL, Yaszemski MJ, Lu L. Poly(propylene fumarate) bone tissue engineering scaffold fabrication using stereolithography: Effects of resin formulations and laser parameters. Biomacromolecules. 2007:8(4):1077-84.

10. Lee JW, Kim JY, Cho DW. Solid free-form fabrication technology and its application to bone tissue engineering. Int J Stem Cells. 2010;3:85-95.

11. Smyth PA, Green I, Jackson RL, Hanson RM. Biomimetic model of articular cartilage based on in vitro experiments. J Biomimetics Biomaterials Biomed Eng. 2014;21:75-91.

12. Klein TJ, Jos Malda J, Sah RL, Hutmacher DW. Tissue engineering of articular cartilage with biomimetic zones. Tissue Eng Part B. 2009;15:143-57.

13. Almeida CR, Serra T, Oliveira MI, Planell JA, Barbosa MA, Navarro M. Impact of 3-D printed PLA- and chitosan-based scaffolds on human monocyte/ macrophage responses: Unraveling the effect of 3-D structures on inflammation. Acta Biomater. 2014;10(2):613-22. 13.

14. Inzana JA, Olvera D, Fuller SM, Kelly JP, Graeve OA, Schwarz EM, Kates SL, Awad HA. 3D printing of composite calcium phosphate and collagen scaffolds for bone regeneration. Biomaterials. 2014;35(13):4026-34.

15. Xu F, Celli J, Rizvi I, Moon SJ, Hasan T, Demirci U. A three-dimensional in vitro ovarian cancer co-culture model using a high-throughput cell patterning platform. Biotechnol J. 2011;6(2):204-12.

16. Serra T, Ortiz-Hernandez M, Elisabeth Engel E, Planell JA, Navarro M. Relevance of PEG in PLA-based blends for tissue engineering 3D-printed scaffolds. Mater Sci and Eng: C. 2014;38:55-62.

17. Park HS, Lee SY, Yoon HS, Noh I. Biological evaluation of micro-patterned hyaluronic acid hydrogel for bone tissue engineering. Pure and Applied Chem. 2014;86:1911-22

18. Fjserholm F, Stegmayr J, Bauer P, Johansson F, Wallman L, Bengtsson M, Oredsson S. Biocompatibility of a polymer based on off-stoichiometry thiolenes + expoxy (OSTE+) for neural implants. Biomater Res. 2015;19:174-83.

19. Choi SC, Yoo MA, Lee SY, Lee HJ, Son DH, Jung J, Noh I, Kim CW. Modulation of biomechanical properties of hyaluronic acid hydrogels by crosslinking agents. J Biomed Mater Res Part A. 2015;103(9):3072-80.

20. Jo S, Kim S, Cho TH, Shin E, Hwang SJ, Noh I. Effects of recombinant human bone morphogenic protein-2 and human bone marrow-derived stromal cells on in vivo bone regeneration of chitosan-poly(ethylene oxide) hydrogel. J Biomed Mater Res Part A. 2013;101A(3):892-901.

21. Subbiah R, Suhaeri M, Hwang MP, Kim W, Park K. Investigation of the changes of biophysical/mechanical characteristics of differentiating preosteoblasts in vitro. Biomater Res. 2015;19:24

22. Kim DH, Hwang KH, Lee JD, Park HC, Yoon SY. Long and short range order structural analysis of in-situ formed biphasic calcium phosphates. Biomater Res. 2015;19:14.

23. Buyukhatipoglu K, Jo W, Sun W, Clyne AM. The role of printing parameters and scaffold biopolymer properties in the efficacy of a new hybrid nanobioprinting system. Biofabrication. 2009;1(3):035003.
24. Tarafder S, Bose S. Polycaprolactone-coated 3D printed tricalcium phosphate scaffolds for bone tissue engineering: in vitro alendronate release behavior and local delivery effect on in vivo osteogenesis. ACS Appl Mater Interfaces. 2014;6(13):9955-65.

25. Hollister SJ. Porous scaffold design for tissue engineering. Nat Mater. 2005;4:518-24.

26. Bose $\mathrm{S}$, Vahabzadeh $\mathrm{S}, \mathrm{Amit} \mathrm{BA}$. Bone tissue engineering using $3 \mathrm{D}$ printing. Materials Today. 2013;16(12):496-504.

27. Patterson J, Martino MM, Jeffrey AH. Biomimetic materials in tissue engineering. Materials Today. 2010;13:14-22.

28. Liu W, L Y, Liu J, Niu X, Wang Y, Li D. Application and performance of 3D printing in nanobiomaterials, J. Nanomaterials. 2013;681050:7. http://dx.doi. org/10.1155/2013/681050.

29. Gao C, Deng Y, Feng P, Mao Z, Li P, Yang B, Deng J, Cao Y, Shuai C, Peng S. Current progress in bioactive ceramic scaffolds for bone repair and regeneration. Int J Mol Sci. 2014;15(3):4714-32.

30. Do AV, Khorsand B, Geary SM, Salem AK. 3D Printing of scaffolds for tissue regeneration applications. Adv Health Mater. 2015;4(12):1742-62.

31. Mohanty S, Larsen LB, Trifol J, Szabo P, Burri HVR, Canali C, Dufva M, Emnéus J, Wolff A. Fabrication of scalable and structured tissue engineering scaffolds using water dissolvable sacrificial 3D printed molds. Mater Sci and Eng C. 2015;55:569-78.

32. Naveena N, Venugopal J, Rajeswari R, Sundarrajan S, Sridhar R, Shayanti M, et al. Biomimetic composites and stem cells interaction for bone and cartilage tissue regeneration. J Mater Chem. 2012;22:5239-53.

33. Tseng AA, Chen K, Chen CD, Ma KJ. Electron beam lithography in nanoscale fabrication: recent development. IEEE Trans Electron Packag Manuf. 2003;26(2):141-9.

34. Guo LJ. Recent progress in nanoimprint technology and its applications. J Physics D Applied Physics. 2004;37(11):R123.

35. Dimov S, Brousseau E, Minev R, Bigot S. Micro- and nano-manufacturing: Challenges and opportunities. J Mech Eng Sci. 2012;226(1):3-15.

36. $\mathrm{Xu} \mathrm{H}, \mathrm{Li} \mathrm{H}$, Chang J. Controlled drug release from a polymer matrix by patterned electrospun nanofibers with controllable hydrophobicity. J Mater Chem B. 2013;1:4182-8.

37. Zhang M, Sun S, Yu X, Cao X, Zou Y, Yi T. Formation of a large-scale ordered honeycomb pattern by an organogelator via a self-assembly process. Chem Commun. 2010;46:3553-5.

38. Kim BC, Moraes C, Huang J, Thouless MD, Akayama S. Fracture-based micro- and nanofabrication for biological applications. Biomater Sci. 2014;2(3):288-96.

39. Li M, Bhiladvala RB, Morrow TJ, Sioss JA, Lew KK, Redwing JM, Mayer TS. Bottom-up assembly of large-area nanowire resonator arrays. Nature Nanotech. 2008;3(2):88-92

40. Kovtyukhova NI, Mallouk TE, Mayer TS. Templated surface sol-gel synthesis of $\mathrm{SiO}_{2}$ nanotubes and $\mathrm{SiO}_{2}$-insulated metal nanowires. Adv Mater. 2003; 15(10):780-5.

41. Kim SO, Solak HH, Stoykovich MP, Ferrier NJ, de Pablo JJ, Nealey PF. Epitaxial self-assembly of block copolymers on lithographically defined nanopatterned substrates. Nature. 2003:424(6947):411-4.

42. Neves NM, Campos R, Pedro A, Cunha J, Macedo F, Reis RL. Patterning of polymer nanofiber meshes by electrospinning for biomedical applications. Int J Nanomed. 2007;2(3):433-48.

43. Kim HN, Kang DH, Kim MS, Jiao A, Kim DH, Suh KY. Patterning Methods for Polymers in Cell and Tissue Engineering. Annals of Biomed Eng. 2012;40(6):1339-55.

44. Lima AC, Mano JF. Micro/nano-structured superhydrophobic surfaces in the biomedical field: part l: basic concepts and biomimetic approaches. Nanomedicine. 2015;10(1):103-19.

45. Lima AC, Mano JF. Micro/nano-structured superhydrophobic surfaces in the biomedical field: part II: applications overview. Nanomedicine. 2015;10(2):271-97.

46. Kyle DJT, Oikonomou A, Hill E, Bayat A. Development and functional evaluation of biomimetic silicone surfaces with hierarchical micro/nanotopographical features demonstrates favourable in vitro foreign body response of breast-derived fibroblasts. Biomaterials. 2015;52:88-102.

47. Losic D, Mitchell JG, Lal R, Voelcker NH. Rapid Fabrication of micro- and nanoscale Patterns by replica molding from diatom biosilica. Adv Funct Mater. 2007:17:2439-46.

48. Andrews HG, Badyal JPS. Bioinspired hook surfaces based upon a ubiquitous weed (Galium aparine) for dry adhesion. J Adhesion Sci and Tech. 2014;28(13):1243-55.

49. Liang J, Song $R$, Huang $Q$, Yang $Y$, Lin L, Zhang $Y$, Jiang $P$, Duan $H$, Dong $X$, Lin C. Electrochemical construction of a bio-inspired micro/nano-textured 
structure with cell-sized microhole arrays on biomedical titanium to enhance bioactivity. Electrochim Acta. 2015;174:1149-59.

50. Armentano I, Bitinis N, Fortunati E, Mattioli S, Rescignano N, Verdejo R, LopezManchado MA, Kenny JM. Multifunctional nanostructured PLA materials for packaging and tissue engineering. Progress in Polym Sci. 2013;38:1720-47.

51. Dvir T, Timko BP, Kohane DS, Langer R. Nanotechnological strategies for engineering complex tissues. Nature Nanotech. 2011;6:13-22.

52. Zhang L, Webster TJ. Nanotechnology and nanomaterials: Promises for improved tissue regeneration. Nano Today. 2009;4:66-80.

53. Fratzl $P$, Weinkamer R. Nature's hierarchical materials. Progress in Mater Sci. 2007;52:1263-334.

54. Huebsch N, Mooney DJ. Inspiration and application in the evolution of biomaterials. Nature. 2009;462:426-32

55. Qiu Z-Y, Chen C, Wang X-M, Lee IS. Advances in the surface modification techniques of bone-related implants for last 10 years. Regen Biomater. 2014;1:67-79.

56. Rammelt S, Illert T, Bierbaum S, Scharnweber D, Zwipp H, Schneiders W. Coating of titanium implants with collagen, RGD peptide and chondroitin sulfate. Biomaterials. 2006;27:5561-71.

57. Pujari SP, Scheres L, Marcelis A, Zuilhof H. Covalent surface modification of oxide surfaces. Angew Chem Int Ed. 2014;53:6322-56.

58. Tanase C, Sartoris A, Popa M, Verestiuc L, Unger R, Kirkpatrick C. In vitro evaluation of biomimetic chitosan-calcium phosphate scaffolds with potential application in bone tissue engineering. Biomed Mater. 2013;8:025002.

59. Kokubo T, Takadama H. How useful is SBF in predicting in vivo bone bioactivity? Biomaterials. 2006;27:2907-15.

60. Shin $\mathrm{H}$, Jo S, Mikos AG. Biomimetic materials for tissue engineering. Biomaterials. 2003:24:4353-64.

61. Chen C, Zhang SM, Lee IS. Immobilizing bioactive molecules onto titanium implants to improve osseointegration. Surf Coat Tech. 2013;228:S312-7.

62. Kango S, Kalia S, Celli A, Njuguna J, Habibi Y, Kumar R. Surface modification of inorganic nanoparticles for development of organic-inorganic nanocomposites-A review. Progress in Polymer Sci. 2013;38:1232-61

63. Wahl D, Czernuszka J. Collagen-hydroxyapatite composites for hard tissue repair. European Cells \& Materials. 2006;11:43-56.

64. Kong X, Cui F, Wang X, Zhang M, Zhang W. Silk fibroin regulated mineralization of hydroxyapatite nanocrystals. J Crystal Growth. 2004;270:197-202.

65. He G, Dahl T, Veis A, George A. Nucleation of apatite crystals in vitro by self-assembled dentin matrix protein. Nat Mater. 2003;2:552-8.

66. Pighinelli L, Kucharska M. Chitosan-hydroxyapatite composites. Carbohydr Polym. 2013;93:256-62.

67. Sangeetha K, Thamizhavel A, Girija E. Effect of gelatin on the in situ formation of Alginate/Hydroxyapatite nanocomposite. Mater Lett. 2013;91:27-30.

68. Vines JB, Lim D-J, Anderson JM, Jun HW. Hydroxyapatite nanoparticle reinforced peptide amphiphile nanomatrix enhances the osteogenic differentiation of mesenchymal stem cells by compositional ratios. Acta Biomater. 2012:8:4053-63.

69. Ma J, Wang J, Ai X, Zhang S. Biomimetic self-assembly of apatite hybrid materials: from a single molecular template to bi-/multi-molecular templates. Biotech Adv. 2014;32:744-60.

70. Wang J, Zhou W, Hu W, Zhou L, Wang S, Zhang S. Collagen/silk fibroin bi-template induced biomimetic bone-like substitutes. J Biomed Mater Res Part A. 2011;99:327-34.

71. Tari NE, Motlagh MMK, Sohrabi B. Synthesis of hydroxyapatite particles in catanionic mixed surfactants template. Mater Chem and Phy. 2011;131:132-5.

72. Brittberg M, Lindahl A, Nilsson A, Ohlsson C, Isaksson O, Peterson L. Treatment of deep cartilage defects in the knee with autologous chondrocyte transplantation. N Engl J Med. 1994;331:889-95.

73. Brittberg M. Autologous chondrocyte implantation technique and long-term follow-up. Injury. 2008;39 Suppl 1:S40-9.

74. Knutsen G, Engebretsen L, Ludvigsen TC, Drogset JO, Grontvedt T, Solheim E, Strand T, Roberts S, Isaksen V, Johansen O. Autologous chondrocyte implantation compared with microfracture in the knee. A randomized trial. Bone Joint Surg Am. 2004;86-A:455-64.

75. Harris JD, Siston RA, Brophy RH, Lattermann C, Carey JL, Flanigan DC. Failures, re-operations, and complications after autologous chondrocyte implantation-a systematic review. Osteoarthritis Cartilage. 2011;19(7):779-91.

76. Khan WS, Adesida AB, Tew SR, Longo UG, Hardingham TE. Fat pad-derived mesenchymal stem cells as a potential source for cell-based adipose tissue repair strategies. Cell Prolif. 2012;45:111-20.
77. Choi WH, Kim HR, Lee SJ, Jeong N, Park SR, Choi BH, Min BH. Fetal cartilagederived cells have stem cell properties and are a highly potent cell source for cartilage regeneration. Cell Transplant 2015. [Epub ahead of print].

78. Williams SK, Amiel D, Ball ST, Allen RT, Tontz Jr WL, Emmerson BC, Badlani NM, Emery SC, Haghighi P, Bugbee WD. Analysis of cartilage tissue on a cellular level in fresh osteochondral allograft retrievals. Am J Sports Med. 2007;35:2022-32.

79. Steadman JR, Rodkey WG, Briggs KK, Rodrigo JJ. The microfracture technic in the management of complete cartilage defects in the knee joint. Orthopad. 1999;28:26-32.

80. Gobbi A, Karnatzikos G, Kumar A. Long-term results after microfracture treatment for full-thickness knee chondral lesions in athletes. Knee Surg Sports Traumatol Arthrosc. 2014;22:1986-96.

81. Negrin $L L$, Vecsei $V$. Do meta-analyses reveal time-dependent differences between the clinical outcomes achieved by microfracture and autologous chondrocyte implantation in the treatment of cartilage defects of the knee? J Orthop Sci. 2013;18:940-8.

82. Anders S, Volz M, Frick H, Gellissen JA. Randomized controlled trial comparing autologous matrix-induced chondrogenesis (AMIC(R)) to microfracture: Analysis of 1- and 2-year follow-up data of 2 centers. Open Orthop J. 2013;7:133-43.

83. Fortier LA, Potter HG, Rickey EJ, Schnabel LV, Foo LF, Chong LR, Stokol T, Cheetham J, Nixon AJ. Concentrated bone marrow aspirate improves fullthickness cartilage repair compared with microfracture in the equine model. J Bone Joint Surg Am. 2010;92:1927-37.

84. Oussedik S, Tsitskaris K, Parker D. Treatment of articular cartilage lesions of the knee by microfracture or autologous chondrocyte implantation: a systematic review. Arthroscopy. 2015;31:732-44.

85. Basad E, Wissing FR, Fehrenbach P, Rickert M, Steinmeyer J, Ishaque B. Matrix-induced autologous chondrocyte implantation (MACI) in the knee: clinical outcomes and challenges. Knee Surg Sports Traumatol Arthrosc. 2014;23(12):3729-35.

86. Huang H, Zhang X, Hu X, Shao Z, Zhu J, Dai L, Man Z, Yuan L, Chen H, Zhou C, Ao Y. A functional biphasic biomaterial homing mesenchymal stem cells for in vivo cartilage regeneration. Biomaterials. 2014;35:9608-19.

87. Lee $\mathrm{CH}$, Cook JL, Mendelson A, Moioli EK, Yao H, Mao JJ. Regeneration of the articular surface of the rabbit synovial joint by cell homing: a proof of concept study. Lancet. 2010;376(9739):440-8.

88. Chang NJ, Lam CF, Lin CC, Chen WL, Li CF, Lin YT, Yeh ML. Transplantation of autologous endothelial progenitor cells in porous PLGA scaffolds create a microenvironment for the regeneration of hyaline cartilage in rabbits. Osteoarthr Cartil. 2013:21(10):1613-22.

\section{Submit your next manuscript to BioMed Central and we will help you at every step:}

- We accept pre-submission inquiries

- Our selector tool helps you to find the most relevant journal

- We provide round the clock customer support

- Convenient online submission

- Thorough peer review

- Inclusion in PubMed and all major indexing services

- Maximum visibility for your research

Submit your manuscript at www.biomedcentral.com/submit 